\title{
Co-Founder of \$600-Million Company Finds Materials Research Eases His Mental Burden Based on an Interview with Tu Chen
}

With three successive degrees in metallur$8 y$, research at the university, and 16 years of materials research experience in industry. Tu Chen, a Taiwanese-born scientist, embarked on a venture, in 1983, that turned into a 600 million-dollar business. Dr. Chen is cofounder and chair of the board of Komag. Incorporated, an independent manufacturer of thin-film disks, the primary storage medium for digital data used in computer hard-disk drives. Komag's corporate headquarters are located in San Jose, California, with U.S. manufacturing facilities in San Jose and Santa Rosa, California, and international manufacturing subsidiaries in Japan, Malaysia, and Thailand. This article is based on MRS Bulletin's interview with Dr. Chen to learn how his materials research background affected his career as an entrepreneur.

\section{Combined, We had 60 Years of Experience}

In the 1960s, I went to the United States for graduate work at the University of Minnesota. Two areas were popular at that time for students of my background: semiconductors and magnetic materials. I decided to take magnetic materials as my major research effort because I was interested in that area since my undergraduate work.

For 13 years at Xerox, I did my research mostly in material for optical devices and data storage applications. That was in the 1970s. During the 1980s, when the computer industry migrated from mainframes to PCs, demand for low-cost, high-capacity data storage devices increased. As a researcher at Xerox in the 1970s, I was conducting research on developing the technology for creating low-cost, high-capacity magneto-optical and magnetic thin-film hard-disk storage devices and materials. In the early 1980s, when the call came for the need for low-cost, high-capacity and small form factor data storage devices, the magnetic thin-film hard-disk memory became the chosen technology to meet the need. Unfortunately magnetic thin-film technology for hard-disk industry applications was still in its infancy. Therefore, more than a couple dozen companies, including some start-up companies, quickly jumped into the act to carry out research and development to try to make the magnetic thin-film media work and replace the limited capacity magnetic oxide technology which was in use for over several decades. So, early in

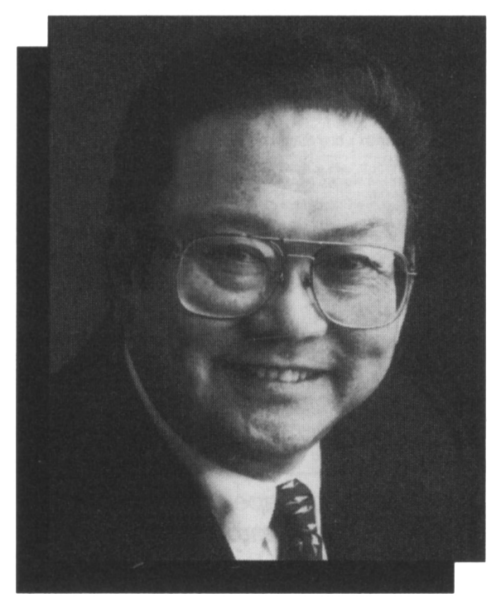

Tu Chen embarked on a venture, in 1983, that tumed into a $\$ 600$-million business. $\mathrm{He}$ is co-founder and chair of the board of Komag, Incorporated, an independent manufacturer of thin-film disks.

1980, as many leading technology companies such as Ampex and Hewlett-Packard jumped into the action, I suggested to Xerox's management that they should support me by taking the results of my research and developing them into a useful device to meet the market demand, but the company declined. With their blessing, however, I obtained their permission to raise the funds to start this company [Komag, Incorporated]. At that time, when I started in the early summer of 1983, we were almost the last ones to raise a venture fund to start this kind of business.

In materials science, I think I am good at creating the magnetic thin-film hard disk necessary for memory applications, but I realized I needed partners who were knowledgeable in storage applications. Therefore I invited two of my good friends, both of whom at that time worked at IBM-one an electrical engineer who is an expert on hard-disk storage integration and application and the other, an extremely good recording physicist and mechanical engineer - to join me. Combined, we had 60 years of experience.

In March 1983, I started to write a busi-

Career Clips explores the range of career possibilities in, or related to, materials science. ness plan and received the first seed money in June. With final major funding of $\$ 5.5$ million accomplished in early September, we started to order the equipment for the production pilot line. In the meantime we started our research and development in a small garage-type shop; and by spring of 1984, we moved into our first factory. By summer of that year we produced some prototype disk samples for customers. By the end of that summer we had our mass production machine installed, and produced the first mass production sample for customers by the end of November of that same year.

The extremely short time- that is, one and a half years from founding the company to achieving a cash-generating business - was a big challenge. This we had to accomplish in order to be a successful start-up company. This was because of the limited cash available and the limited market window for the product. To be successful, you have to quickly establish yourself to be recognized as a viable component supplier within the time window needed.

By the end of 1984, even though we were able to commercialize the product, the original funds were exhausted. To be able to become a viable supplier, we needed to expand our capacity. Unfortunately, the U.S. financial market was in poor shape, and it was almost impossible to obtain new financing for the expansion. Fortunately at that time the Japanese market was booming, and they were looking to invest in new technology. Therefore we were able to obtain our second financing through their investment and also at the same time establish a jointventure company in Japan to expand our business worldwide.

The most exciting moment for me at Komag was when we went public in the spring of 1987: After hard competition, we were the first company to go public as an independent hard-disk media supplier.

When asking how Komag became successful, the answer-besides having the good technological skill, hard work, and good luck-is the spirit of teamwork. In addition to my two technical friends, we were able to attract a seasoned business manager to become the president and cofounder of the company and thus help build a team to run the business side of the company. Since its founding, the company has been based on making the best product 
for the market, using the most innovative way of creating the products. The so-called "innovative way" does not only involve creating a differentiable product, but also a low-cost manufacturing process to meet the competition. In order to achieve this goal, we had to have multi-talented researchers to carry out the $R \& D$. This is because the hard-disk drive is an electromechanical device. Therefore, the research involves not only materials science to create the hard-disk media, but also mechanical engineering to create a product to meet the severe mechanical environmental requirements and electrical engineering for dealing with the sophisticated electromagnetic signal-processing demand.

In addition to materials scientists, we have a large team of researchers consisting of mechanical, electrical, and chemical engineers as well as physicists and chemists. To begin making hard-disk media, we needed materials scientists (metallurgists) and mechanical engineers to develop the aluminum substrate or glass / ceramic substrate to meet the mechanical requirements of the disks; chemists and chemical engineers to plate the $\mathrm{NiP}$ on the aluminum substrate; and mechanical engineers, materials scientists, and chemists to polish and clean the disks.

Usually, most people neglect how important the disk-cleaning step is. As a matter of fact, the cleaning step in producing hard disks is a very difficult task because on top of the cleaned disk substrate surface, the crystallites of the seed and the magnetic films have to grow properly during the film deposition process in the vacuum-sputtering process. Poorly cleaned surfaces not only cause physical defects on the media, but also cause nonuniformity in magnetic properties of the film by altering the crystal structure and orientation of the microcrystallites in the magnetic film from its norm.

Research on film deposition of magnetic film is one of the most interesting in materials science because the micro-magnetic properties of the film are strongly related to intrinsic properties of the magnetic alloy as well as to extrinsic properties such as crystalline and the microcrystalline structure and crystal orientation. Furthermore, all these extrinsic and some intrinsic properties of the film are strongly affected by nucleation and the growth process of the films which, in turn, are influenced by the film-growth environment and kinetics of the film deposition process. Mastering the vacuum deposition process for the film and carbon overcoat is a must for creating a differentiable product for our customers.

\section{Research is My Tranquilizer}

My favorite hobby is to do research. But in order to support my hobby, we needed to create a business even though I do not enjoy the business side very much. It takes a lot out of you to run a business. You have a day-to-day worry about customers, competitors, financial market, national and world economy as well as the livelihood of thousands of people in your company. Fortunately, I love research; therefore, every day I allocate a certain portion of my time to work on the research on many subjects with young researchers and engineers to solve technical problems, to understand the fundamentals of materials science, and to create new products. So the research activity of my daily life becomes my tranquilizer for living in this crazy business world. In this aspect I am luckier than most company chairs of this type of business because my love for research keeps me sane.

... the research activity of
my daily life becomes my
tranquilizer for living in this
crazy business world.

As for the field of research, I know in my life that I am not smart enough to do academic research to get a Nobel prize, so I choose to stay in applied research. The mode of applied research that I do is at first to understand as deeply as possible the physical phenomenon between the process and the structure of a material, and also its effect on intrinsic as well as extrinsic properties of the resultant product. The understanding gleaned from this will allow me to create a materials science roadmap, and the roadmap will then be used to create a product for commercial use. This kind of research is very exciting and challenging because the feedback on success or failure of your research is very rapid.

Why is this kind of research so challenging? Because if you have a product in mind, the process you invented must be practical and the product must be able to be manufactured on a commercial scale. Therefore the knowledge you must have to create the roadmap must consist of not only the material and structure of the material, but also extensive knowledge of the process equipment and environment in order to be able to create a practical and competitive product.

When asked which invention makes me most proud, I cannot give a simple answer. The technology is complex and involves more than a single invention to make a product, and it also changes so fast. However, the one type of product Komag made which I feel most proud of is the "isotropic media" produced at ambient temperature during the film deposition process. This type of product was created based on a combination of understanding of fundamental nucleation and growth theory and the design of materials and equipment to produce a superior harddisk media at ambient temperature. The product and processes are different from all of our competitors', and we are the only company that can produce the hard disk at ambient temperature. This process allows us to eliminate the complex effect of temperature on stress, uniformity, and manufacturability of the hard disk. Many different generations of products were made based on this type of "isotropic media," and it has endured for 14 years to this date. Of course, as the demand for further storage density increases, it requires us to change the basic process completely. Recently we were able to create a new roadmap based on fundamental materials science to make the change in a very short time because of our extensive knowledge.

\section{Plan to Retire Early Enough So I Can Start on My New Career}

Materials science has turned out to be perfect for me. By default, I became a metallurgist-not by choice. Now when I think about it I probably can adapt to any subject so long as it involves research for new knowledge. Today I still enjoy research in physics and chemistry, and in the applied sciences such as materials science. However, like most of the researchers in physical sciences, when I retire I would like to study other fields of science such as astrophysics or anthropology. Recently I have started to spend time studying anthropology, particularly the anthropology of civilization. I am interested in knowing how our civilization evolved to the way it is today, and how it may evolve in the future.

To prepare for my retirement, I have identified and hired a very capable successor (more capable than I) to carry the technology burden of my position in the company. I am dedicated to helping my successor succeed in carrying out his responsibilities and to being a mentor for setting future technological direction. I do not mind helping on a part-time basis even after I retire. 